\title{
Editörden
}

Editorial

\section{Hemofili Hastalarında Klinik Yaklaşım ile Ağız ve Diş Sağlığının Önemi}

\author{
Clinical Approach and The Importance of Oral Health in \\ Patients With Hemophilia
}

Ayşem Yurtseven Günay ${ }^{1}$ (D) , Gülsüm Ak² (D)

\section{ÖZET}

Faktör VIII veya IX eksikliğinde görülen hemofili, nadir görülen bir konjenital kanama bozukluğudur. Hemofili hastalarında diş hekimliğinde uygulanan invaziv tedaviler kanama riski oluşturur. Ayrıca oral hijyen eksikliğinde görülen dişeti iltihabı uzayan spontan kanamalara sebep olabilir. Bu hastalarda klinik yaklaşımdaki farklııklara dikkat edilmeli ve hematolog konsültasyonu ile kanama kontrolü önlemleri alınmalıdır. Ayrıca oluşabilecek ağız hastalıklarını azaltmak için ağız hijyeni, diyet, koruyucu uygulamalar gibi unsurların üzerinde durulmalıdır.

Anahtar Kelimeler: Hemostatik yöntemler; Kan koagülasyon bozuklukları; Oral kanama

\begin{abstract}
Hemophilia seen in factor VIII or IX deficiency is a rare congenital bleeding disorder. Invasive dental treatments in hemophilia patients pose a risk of bleeding. In addition, gingivitis seen in lack of oral hygiene can cause prolonged spontaneous bleeding. In these patients, attention should be paid to differences in clinical approach and bleeding control measures should be taken with hematologist consultation. Moreover, factors such as oral hygiene, diet, and protective practices should be emphasized in order to reduce oral diseases that may occur.
\end{abstract}

Keywords: Blood coagulation disorders; Hemostatic techniques; Oral hemorrhage

Makale gönderiliş tarihi: 16.08.2021 ; Yayına kabul tarihi: 24.10.2021

İletişim: Dr. Ayşem Yurtseven Günay

İstanbul Üniversitesi Diş Hekimliği Fakültesi, Prof.Dr.Cavit Orhan Tütengil Sokak.No.4 Vezneciler-Fatih-iSTANBUL

E-posta: aysem.yurtsevengunay@istanbul.edu.tr

${ }^{1}$ Öğr. Gör. Dr., İstanbul Üniversitesi Diş Hekimliği Fakültesi, Ağız Diş ve Çene Cerrahisi Anabilim Dalı, İstanbul/Türkiye

${ }^{2}$ Prof. Dr., İstanbul Üniversitesi Diş Hekimliği Fakültesi, Ağız Diş ve Çene Cerrahisi Anabilim Dalı, İstanbul/Türkiye 


\section{GíRiş}

Hemofili, faktör VIII veya IX eksikliği sonucunda gelişen nadir bir kalıtsal kanama bozukluğu olup, eklem içi ve kas içi kanamalarla karakterize bir hastalıktır. Faktör VIII eksikliği Hemofili A, faktör IX eksikliği ise Hemofili B olarak adlandırıır. ${ }^{1}$

Hemofili A yaklaşık 10.000 doğumda 1 olarak görülürken, sıkığı Hemofili B'ye göre 5-6 kat daha fazladır. Tüm hemofiliklerin \%85'ini Hemofili A, \%15 kadarını ise Hemofili B oluşturmaktadır. ${ }^{1}$

Erken çocukluk döneminde kolay ekimoz oluşumu, özellikle eklem içi ve kas içi spontan kanamaların varlığı ve girişimler ya da travma sonrası beklenenden uzun süren kanama öyküsünün varlığı hemofiliyi akla getirmelidir. Kanama bulguların ağırığı faktör VIII veya IX'un eksiklik derecesiyle doğrudan ilişkilidir. Faktör aktivitesi <\%1 olan hastalar "ağır hemofili" kliniği gösterirken, \%1-5 arasında olanlar "orta hemofili" ve $>\% 5$ olanlar "hafif hemofili" kliniği gösterirler. ${ }^{1}$

Konjenital kanama bozukluğu olan hastalar, diş tedavileri sonrasında kanama riski taşıyabilirler. Bazı hastalarda kanama çok şiddetli, nadiren yaşamı tehdit edici seviyede olabilir. 1970'lerden sonra gelişmeye başlayan faktör konsantreleri, desmopressin (DDAVP) ve antifibrinolitik ajanlar ile postoperatif komplikasyonlar belirgin düzeyde azalmıştır. Bununla birlikte, halen diş tedavileri kanama bozukluğu olan hastalar için öncelikli kanamaya eğilim sebepleri arasında yer almaktadır. ${ }^{2}$

Diş tedavilerinin gereksinimini azaltmak, ağız hijyeninin doğru ve düzenli bir şekilde sağlanması ile mümkündür. Ancak kanama bozukluğu olan hastalarda çoğunlukla kötü ağız hijyeni varlığı bildirilmektedir. ${ }^{3-5} \mathrm{Bu}$ da sadece tedaviye bağlı oluşacak kanama riskini değil, ağızda görülen hastalıklara bağı oluşabilecek spontan kanama riskini de arttırmaktadır. Bu hastalarda ağız sağlığının yeterli düzeyde sağlanamamasında Moosaje ve ark. ${ }^{5}$ bazı faktörlerin etkili olduğunu öne sürmüşlerdir:

- Kanama korkusu

- Diş hekiminin durumlarını ve bu hastalığın yönetimini anlamasıyla ilgili endişe duyma (diş hekimlerine güven eksikliği)

- Tıbbi geçmiş ayrıntılarının ifşa edilmesine ilişkin endişe (Hepatit ve HIV durumu)

- Diş hekimliği işlemlerine duyulan kaygı

- Tıbbi müdahalelere karşı bıkkınlık

- Ağız hijyenine düşük öncelik verilmesi

\section{Hemofili hastalarına klinik yaklaşım}

Hemofili A ve Hemofili B gibi pıhtılaşma bozukluğuna sahip hastalarda diş hekimliği uygulamaları farklı bir tedavi yaklaşımını gerektirmektedir.

Bu bireyler diş hekimliği kliniklerine genellikle tanıları koyulmuş olarak gelirler. Illk tanı genellikle düşmeye ya da yaralanmaya bağlı durmayan burun kanaması, eklem veya kas içi kanamalar, subkutan ekimoz, yumuşak dokuda hematom gibi belirtilerle konmaktadır. Ancak tanısı olmayan hastalarda özellikle invaziv cerrahi prosedürler veya yaralanmalardan sonra aşırı ve uzayan kanama öyküsünün ya da ailede kanama bozukluğunun var olup olmadığını sorgulamak fikir verebilir. Diş çekimi sonrasında uzayan kanamalar da kanama bozukluğunun ilk tanısının koyulmasını sağlayabilmektedir. ${ }^{6}$ Hastaların farklı sistemik hastalıkları olup olmadığı ve kan transfüzyonlarına bağı bulaş gösterebilen HIV, HBV, HCV, HAV gibi enfeksiyonların varlığı sorgulanmalıdır. ${ }^{7}$

Kapsamlı bir muayene tüm hastaların yönetiminde temeli oluşturur. ${ }^{8}$ Kanama bozukluğu olan hastalarda da rutin uygulanan klinik ve radyografik muayene yöntemleri kullanılır. İntraoral muayene esnasında sond ile dişetinde ve yumuşak dokularda travma oluşturulmamalıdır. Muayene aşamasında hastalara mutlaka ağız hijyeni eğitimi verilmeye başlanmalıdır. Günde 2 kere florürlü diş macunu ile orta yumuşaklıkta fırça yardımıyla doğru teknik kullanılarak dişler fırçalanmalıdır. ${ }^{9,10}$ Eklem problemi sebebiyle manuel fırça kullanımında zorlanma söz konusu ise, modifiye ya da elektrikli fırçalardan faydalanılabilir. ${ }^{9}$ Fırçalama sonrası su ile çalkalama yapmadan sadece tükürme önerilir. ${ }^{10}$ Gerekli görülür ise triklosan ya da klorheksidin içerikli gargara kullanımı önerilebilir. ${ }^{7}$

Klinik ve radyografik muayenenin ardından tanı ve uygun görülen tedavi kaydedilerek bir tedavi planlaması oluşturulur. Hangi bölgelere ne işlemler yapılacağı, kaç seansta tedavi uygulamalarının planlandığı ayrıntılı bir şekilde hematolog için yazılan konsültasyon formunda belirtilmelidir.

Hemofili hastalarında diş çekimi veya ağız boşlu- 
ğu içindeki diğer invaziv prosedürler (dental implant, periodontal cerrahi uygulamaları gibi), bir hematolog konsültasyonu ve hemostaz yönetimi için kişiselleştirilmiş bir planla yapılmalıdır. ${ }^{10}$

Dental tedaviler öncesinde uygulanacak ilaçlar ve dozları hematologlar tarafından belirlenir. Plazma kaynaklı veya rekombinant faktörler, protrombin kompleks konsantreleri, ACE 910, desmopressin asetat, traneksamik asit, epsilon amino kaproik asit, kriyopresipitat gibi ajanlar kullanılabilir. ${ }^{10}$ Diş hekimliğinde uygulanan her işlemde premedikasyon (faktör replasmanı gibi) gerekli değildir (muayene, oklüzal restorasyon, flor uygulaması, fissür örtücü uygulaması, supragingival diş eti tedavileri, endodontik tedavi gibi). ${ }^{3,10}$

Hemofili hastalarında hematolog tarafından oluşturulmuş bireysel plan ile tedaviler yapılır. Faktör replasmanı gerektirmeyen tedaviler dışındaki kanama riskinin orta ve yüksek olduğu işlemlerde mutlaka lokal hemostatik ajanlar hazır bulundurulmalıdır.

Özellikle kanama riski olan tedavilerde hastalar tedavi sonrası dinlendirilmeli ve kanama kontrolü yapıldıktan sonra taburcu edilmelidir. Lokal hemostaz yöntemlerinin yeterli olmadığı düşünülürse mutlaka hematoloğa yönlendirilmelidir. Belirli aralıklarla yapılan tedavi sonrası kontroller ise tedavinin başarısının kontrolü açısından önemli olduğu gibi rutin dental muayenenin yapılması, ağız hijyenin düzenli bir şekilde sağlanıp sağlanmadığının kontrolü ve koruyucu uygulamaların gerekliliğinin değerlendirilmesi açısından da önemlidir.

\section{Hemofili Hastalarında Kanama Sıklığı}

Ağızdaki dokular ve mukoza, pıhtılaşma sistemi bozukluğu olan hastaların operasyon sonrası kanama riskini arttıracak biçimde birçok fizyolojik faktör taşır. Bunlardan biri ağız dokularının damarlanmasının deridekinden çok daha fazla olması, bir diğer faktör de fizyolojik olarak önemli fibrinolitik aktivite göstermesidir. Hemofilik bireylerde çoğu diş tedavileri mutlaka hastane ortamında ve hastanın doktoru ve konu ile ilgili uzmanların yakın işbirliği halinde gerçekleştirilmelidir. ${ }^{11}$

Yapılan bir çalışmada faktör VIII eksikliği olan hastalarda \%29.1 oranında kanama sıklığı tespit edilmiştir. Bunun \%9 unun oral yapılardan kaynaklandığı bildirilmiştir. ${ }^{12}$
Faktör VIII ve faktör IX eksikliği olan hastalarda oral kanamaların sıklığı lokalizasyona göre:

- Diş etinde \%64

- Pulpada \%13

- Dilde \%7.5

- Dudakta \%7

- Damakta \%2

- Dukkal mukozada \%1 oranında tespit edilmiştir.

\section{Hemofili hastalarında en sık görülen oral problemler}

Hemofili hastalarında en sık görülen oral problemler; hemofili olmayan bireylerdekine benzer şekilde diş çürükleri, periodontal hastalıklar, akut ve kronik abseler, gömülü dişler, kanamalar, ortodontik problemler ve ağrıdır.

Hemofili hastalarında diş çürüklerinin (Resim 1) daha fazla olduğunu bildirilen çalışmalar mevcuttur. ${ }^{14,15}$ Çürük oluşumunda diş fırçalarken kanama oluşma korkusu nedeniyle ağız bakımının ihmal edilmesi, yüksek oranda şekerli gıdalarla beslenilmesi, tükürük yapısı ve miktarındaki değişimler gibi pek çok faktör etkili olabilir.

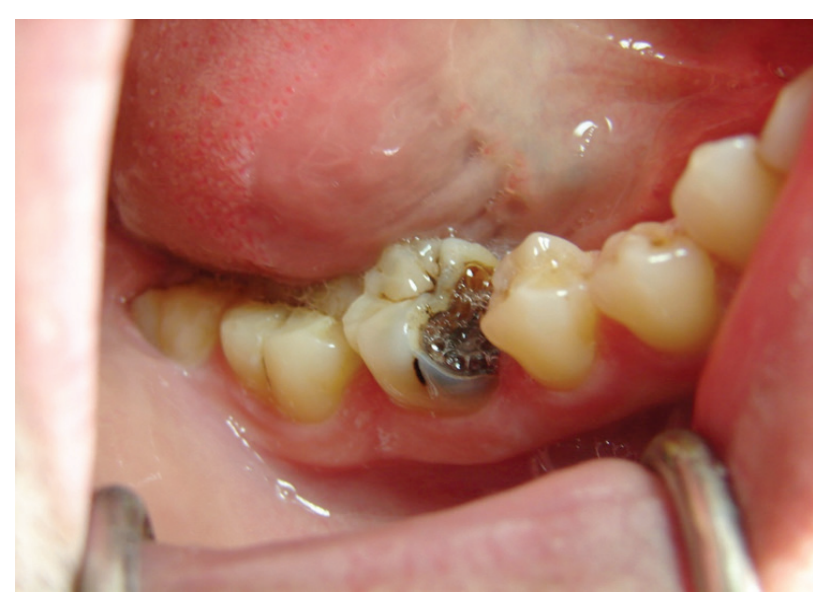

Resim 1. Bir hemofili hastasının sağ alt 1. büyük azı dişinde görülen derin dentin çürüğü

Çürük tedavisi için uygulanan restoratif işlemlerin çoğu düşük risklidir ve faktör replasman tedavisine intiyaç duyulmadan gerçekleştirilebilir. ${ }^{3,10}$ İlerleyen çürükler endodontik tedavi gerektirir. Apikal foramende vital pulpa mevcutsa, bir süre kanama ve ağrı olabilir. Ancak rutin uygulanan sodyum hipoklorit ile irrigasyon ve kalsiyum hidroksitli pat kullanımlarının kanamayı en aza indirdiği belirtilmektedir. ${ }^{8}$ Yine ağız 
hijyeninin yeterli bir şekilde sağlanamaması sebebi ile bu hastalarda ciddi dişeti hastalıkları (Resim 2) görülmektedir.

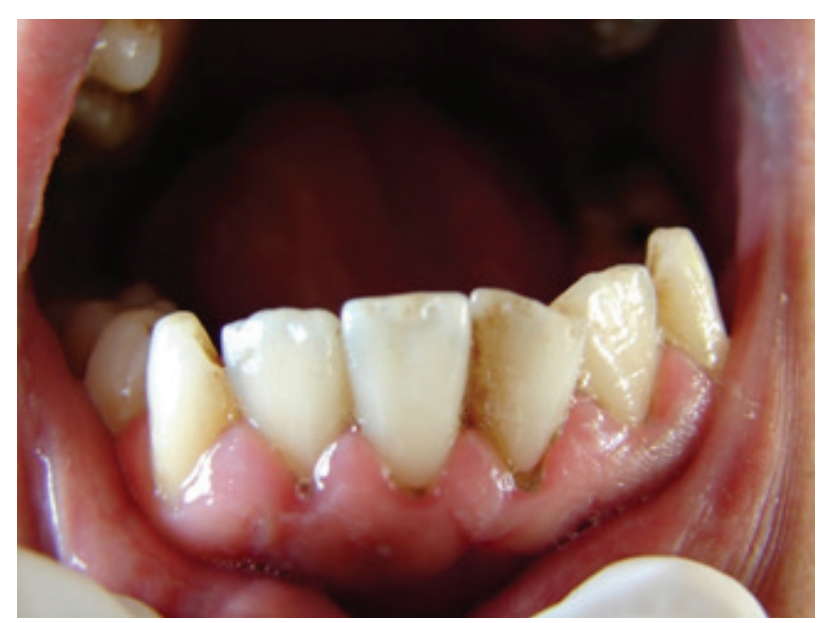

Resim 2. Hemofili hastasında gingivitisin klinik görünümü

Diş eti tedavisi için uygulanan detertraj, küretaj gibi işlemler subgingival olduğunda ve periodontal cerrahi gerekliliğinde yüksek kanama riski mevcuttur., ${ }^{7,10}$ Antifibrinolitik ajanlar kullanılarak tedavi sağlanabilir. Supragingival uygulanacak tedavilerde ise kanama riski düşük olarak bildirilmektedir. ${ }^{3}$

İlerlemiş ve tedavi edilmemiş çürüklerin oluşturduğu apikal itihaba bağlı olarak akut veya kronik abseler oluşabilir (Resim 3). Abse tedavisi cerrahi tedavilerdeki prensiplere uygun olarak gerçekleştirilir. Antibiyotik reçete edileceğinde penisilin ilk tercihtir. Hem aerobik hem de anaerobik bakterileri etkilemek için metronidazol ile birlikte de reçete edilebilir. Penisiline alerjisi olan hastalarda eritromisin veya klindamisin tercih edilebilir. ${ }^{7}$

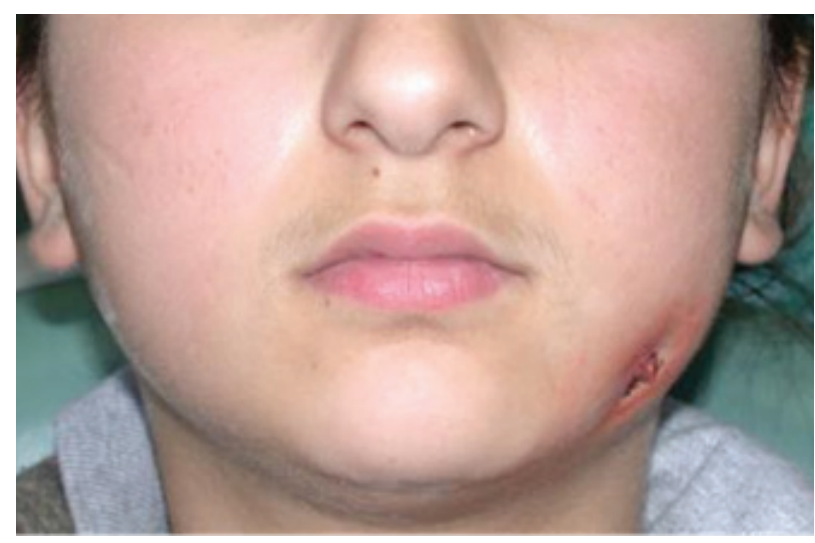

Resim 3. Kanama bozukluğu olan bir hastanın sol alt azı bölgesinde oluşan dental absenin ekstraoral görüntüsü

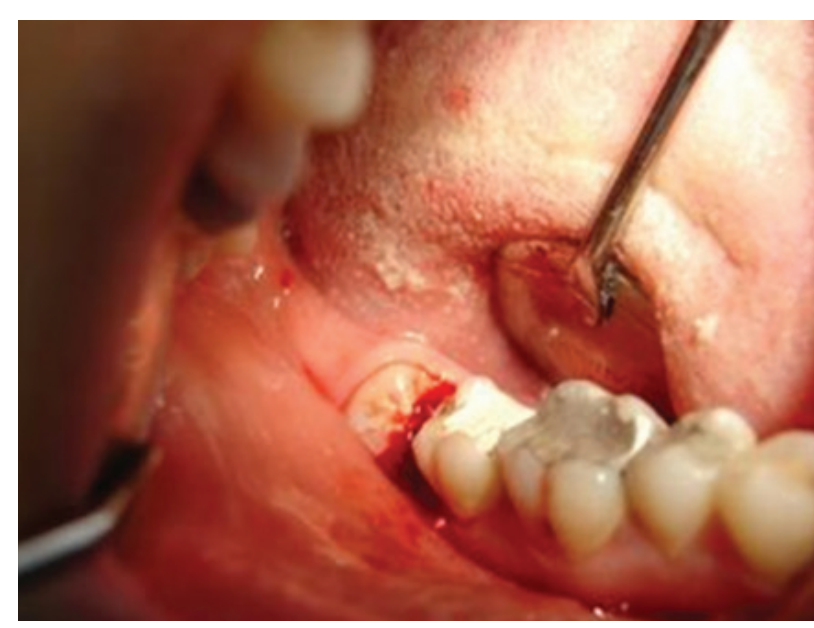

Resim 4. Sağ alt 3. molar diş cerrahisi gerektiren bir hemofil hastasının intraoral görüntüsü

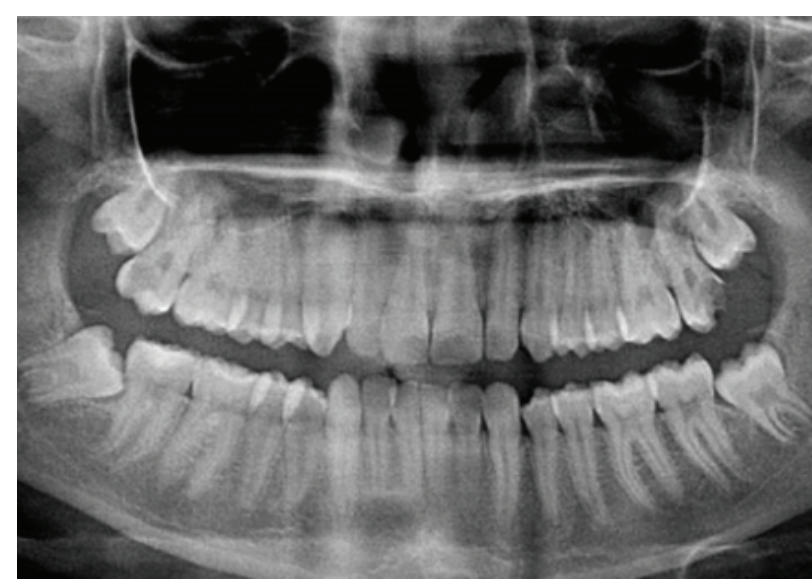

Resim 5. Tüm yirmi yaş dişlerinin gömülü olduğu bir hemofili hastasının panoramik röntgen görüntüsü

Gömülü dişlerin (Resim 4-5) çekimi gerekiyor ise minimal invaziv dental cerrahi girişimi yaklaşımı uygulanır. Hematolog konsültasyonu ve oluşturulan bireysel plan uygulanarak ve lokal hemostatik önlemler alınarak operasyon yapılabilir.

Ağızdaki kanamaların en yaygın nedenleri diş çekimi, diş eti kanaması (genellikle kötü ağız hijyeni nedeniyle) ve travmadır (Resim 6). ${ }^{10}$ Diş çekimi sonrasında oluşabilecek kanama ile ilgili önlemler "Hemofili hastalarında dentoalveolar cerrahi girişimler" bölümünde anlatılacaktır.

Diş eti kanaması, gingivitis işaretidir ve konjenital kanama bozukluğu kaynaklı değildir. Gingivitis için uygulanan periodontal tedavi yöntemleri ile tedavi edilebilir. Uygun periodontal tedavi ve tedavi sonras öneriler ile diş fırçalama sonrası kanama azalacak, diş eti hastalığının ilerlemesi önlenecek ve erken diş kaybı olasılığı düşecektir. ${ }^{10}$ 


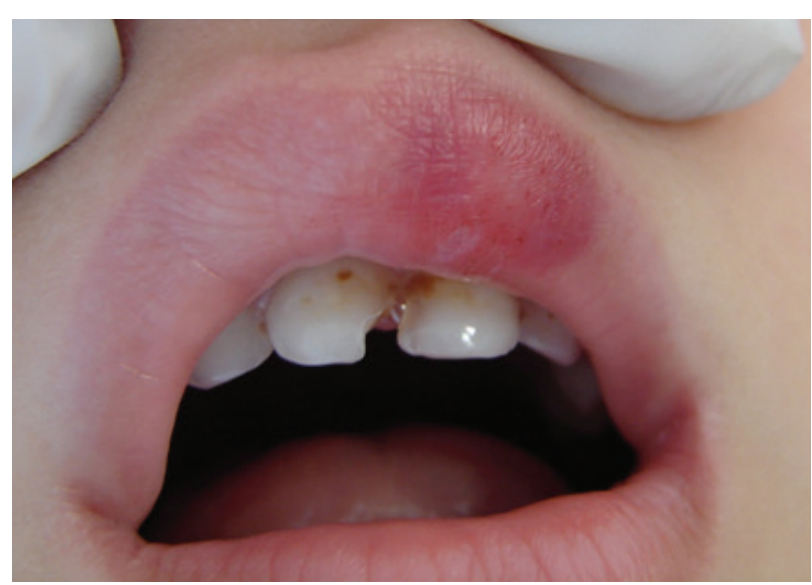

Resim 6. Düşme sonucu üst dudak ve üst santral dişlerde travmanın görüldüğü hemofili hastasının klinik görüntüsü

Oral kanamaların daha az yaygın nedenleri arasında kendine zarar verme, süt dişlerinin dökülmesi ve uygun hemostatik önlemlerin alınmadığı dental işlemler sayılabilir.

Süt dişlerinin kaybını izleyen kanama, erken fark edilir ve tedavi edilirse genellikle uzamaz. Nemli bir gazlı bez kullanılarak diş kaybının olduğu bölgeye en az 15-30 dakika doğrudan basınç uygulanmalıdır. Kanama 6 saatten uzun sürerse ek destek için hemofili tedavi merkezlerine danışılmalıdır. ${ }^{10}$

Bir başka sık görülen durum da ortodontik problemlerdir. Sabit ve hareketli ortodontik apareyler uygulanmadan önce mutlaka koruyucu uygulamaların ve ağız hijyeni motivasyonunun sağlanması gereklidir. Ağır kanama bozukluğu olan hastalar tedavi edilirken, diş etinin zarar görmemesini sağlamak için özel dikkat gösterilmelidir. ${ }^{8}$

Ağızda görülen ilerlemiş hastalıkların (derin diş çürükleri, diş eti iltihabı, abse gibi) çoğunda ağrı semptomu görülür.

Hemofili hastalarında kullanılan analjezikler arasında parasetamol/asetaminofen, selektif COX-2 inhibitörleri (diğer NSAID’ler önerilmez), tramadol veya opioidler bulunur. ${ }^{10}$

Oral bölge kaynaklı ağrılar genellikle asetaminofen ile kontrol edilebilir. Trombosit agregasyonu üzerinde etkisi olduğu için aspirinden kaçınılır. ${ }^{7}$

Sıklıkla görülen bu problemlerin yapılan bazı çalışmalarda daha kötü ağız sağlığına sebep olduğu ${ }^{15,16}$ ve yaşam kalitesini düşürdüğü saptanmıştır. ${ }^{5,14} \mathrm{Hem}$ yaşam kalitesini yükseltmek, hem de tedavi intiya- cını azaltmak için hastaların oral hijyen eğitimi her zaman ön planda tutulmalıdır. Oral hijyen eğitiminin yanında beslenme önerileri, flor ve fissür örtücü uygulamaları gibi koruyucu uygulamaların yapılması, düzenli kontrollerin sağlanması da oldukça önemlidir. ${ }^{8}$

\section{Hemofili hastalarında en sık yapılan Ağız, Diş ve Çene Cerrahisi tedavileri;}

- Diş çekimleri,

- Gömülü diş çekimleri,

- Odontojenik kist operasyonları,

- Apikal rezeksiyon,

- Preprotetik cerrahi uygulamalardır.

\section{Hemofili hastalarında dentoalveolar cerrahi girişimler}

Kalıtsal kanama bozukluğu olan hastalarda herhangi bir cerrahi tedavi hem cerrah hem de hasta için zorlayıcı olarak görülür. Cerrahın hastayla ilgili detaylı planlama yapması ve konsültasyon yapması gerekirken, kanamaya bağlı komplikasyonlar nedeniyle hastanın kendisi müdahaleden ve bunun olası sonuçlarından tedirgin olur. ${ }^{17}$

İnvaziv dental uygulamalar öncesi koagülasyon faktör seviyesinin her bir hasta için ayrı bir tedavi planı gerekli olmakla birlikte, minimum \%50 olmalıdır ${ }^{17}$, tekrarlanan bir doz gerekebilir. İşlemler öncesinde hematolog tarafından oluşturulan bireysel plana göre hareket edilmelidir.

Hastalarda kanamanın az olması için minimum travma ve işlem sonrasında hemorajinin kontrol altına alınması cerrahinin temel prensiplerindendir. Hemofili gibi koagülasyon bozukluğu olan hastalarda bu altın prensibe daha fazla dikkat edilmelidir. ${ }^{2,11}$ Herhangi bir invaziv prosedürden önce hemostaz yönetimi bir hematoloğun tavsiyesi altında bireysel olarak planlanmalıdır. Sistemik veya topikal antifibrinolitikler (traneksamik asit veya epsilon amino kaproik asit), dental müdahalelerinin öncesinde ve sonrasında yardımcı tedavi olarak etkilidir. Bu ajanlar ayrıca faktör replasman tedavisi intiyacını azaltma potansiyeline sahiptir. ${ }^{10}$

Hemofili hastalarında genel anesteziden mümkün olduğunca kaçınılmalıdır. Çünkü entübasyon sırasında laringeal kanama ile karşılaşılma intimali mevcuttur. ${ }^{18}$ Dental prosedürler için çoğunlukla lokal 
anestezi gerekli ve yeterlidir. Lokal anestezi genellikle güvenli bir şekilde uygulanabilir. Ancak inferior alveolar sinir bloğu, superior alveolar sinir bloğu, ağız tabanına ya da vasküler lingual dokulara enjeksiyonlar gibi daha yüksek riskli kas içi oral enjeksiyonlar hematom riski taşımaları açısından sistemik hemostatik önlemler gerektirir. Bu önlemler, bir hematoloğun tavsiyesi altında işlem öncesinde oluşturulmalıdır. İnferior alveolar sinir bloğuna alternatif olarak intraligamenter anestezi veya bukkal infiltrasyon enjeksiyonu gibi düşük riskli anestezi metotları kullanııması düşünülebilir. ${ }^{10}$

Hemofili hastalarında dental enjeksiyonlar için vazokonstriktörlü lokal anestezilerin tek kullanımlık ince bir enjektör ile yavaşça uygulanması kanama açısından düşük risklidir. ${ }^{10,19}$ Diş çekimi sonrası kanama kontrolünde sütür uygulanması, topikal antifibrinolitikler, oksidize selüloz ve fibrin sealant gibi lokal hemostatik ajanların kullanımı önerilir. ${ }^{10}$ Zanon ve ark. ${ }^{20}$ çalışmalarında, hemofili hastalarında rezorbe olmayan ipek dikiş materyalinin kullanılmasını önermişlerdir. Goldmann ve ark. ${ }^{17}$ ise rezorbe olabilen dikişlerin kullanımının yara iyileşmesini daha olumlu etkilediğini bildirmiştir. Brewer ve ark. ${ }^{21}$ her iki dikiş materyalinin kullanılabileceğini ancak yüksek kanama riski olduğunda rezorbe olmayan dikişlerin alımında hemostatik önlemlerin değerlendirilmesi gerektiğini bildirmiştir.

Hastalara çekim soketindeki pıntı ve yara iyileşmesini bozmamak için ameliyat sonrası minimum 3-5 gün yumuşak bir diyet ile beslenmeleri ve yara bölgesini dikkatli bir şekilde fırçalamaları tavsiye edilmelidir. ${ }^{10}$

Hemofili hastalarında gömülü yirmi yaş dişi çekimleri, apikal rezeksiyon, kist operasyonları, dental implant uygulamaları gibi diğer cerrahi işlemler de hematolog tarafından belirlenen bireysel plan dahilinde ve operasyon sırası ile sonrasında alınacak lokal hemostatik önlemler ile güvenle uygulanabilmektedir. ${ }^{3,10,17}$

\section{SONUÇ}

Hemofili hastalarında ağız ve diş sağlığının optimal düzeyde tutulması intraoral bölgenin spontan kanamalarını engellemek, gelecekteki tedavi intiyacını azaltmak, uygulanacak tedavileri basit operasyonlar seviyesinde tutmak, komplikasyon riskini azaltmak, ağız hastalıklarına bağlı faktör kullanımlarını azalt- mak ve yaşam kalitesini artırmak açısından önemlidir. Bu nedenle hastaların ağız hijyeni motivasyonları ön planda tutulmalı ve düzenli kontrol muayeneleri ile gerekli profilaksi uygulamaları yapılmalıdır. Uygulanması gerekli olan dental tedaviler ise dikkatli bir yaklaşım gerektirir.

\section{KAYNAKLAR}

1. Derneği TH. Hemofili Tanı ve Tedavi Kılavuzu; 2011.

2. Açıkgöz MM, Şenol Güven G, Zülfikar B, Ak G. Oral cerrahide hemofili hastalarına güncel yaklaşımlar. İstanbul Üniversitesi Diş Hekimliği Fakültesi Dergisi 2013:33-40.

3. Rahman A, Nizarali N, Dougall A, Daly B. U.K. Hemophilia treaters' knowledge of risk assessment for prolonged bleeding associated with dental procedures. Spec Care Dent 2019;39(2):173-179.

4. Fiske J, McGeoch RJ, Savidge GF, Smith MP. The treatment needs of adults with inherited bleeding disorders. J Disabil Oral Heal 2002;3(2):59-61.

5. Moosajee SHY, Rafique S, Nizarali N, Newton T, Daly B, Bevan D. Oral health status and oral health related quality of life in patients with congenital bleeding disorders. J Disabil Oral Heal 2013;14(4):135-144.

6. Rydz N, James P. Approach to the diagnosis and management of common bleeding disorders. Semin Thromb Hemost 2012;38(7):711-719.

7. Umar D, Baroudi K, Kaul R, Shastry S. Hemophilia A: Denta considerations and management. J Int Soc Prev Community Dent 2014;4(6):147.

8. Brewer AK, Roebuck EM, Donachie M, et al. The dental management of adult patients with haemophilia and other congenital bleeding disorders. Haemophilia 2003;9(6):673-677.

9. Scully C, Diz Dios P, Giangrande P. Oral Care for People with Hemophilia or a Hereditary Bleeding Tendency. Wfh 2008;2(27):1-11.

10. Srivastava A, Santagostino E, Dougall A, et al. WFH Guidelines for the Management of Hemophilia , 3rd edition. 2020:1-158.

11. Zülfikar B, Ak G. Hemofili El Kitabı. İstanbul: Türkiye Hemofili Derneği Yayınları; 1997.

12. Sonis AL, Musselman RJ. Oral bleeding in classic hemophilia Oral Surgery, Oral Med Oral Pathol 1982;53(4):363-366.

13. Adeyemo TA, Adeyemo WL, Adediran A, Akinbami AJA Akanmu AS. Orofacial manifestations of hematological disorders: Anemia and hemostatic disorders. Indian J Dent Res 2011;22(3):454-461.

14. Alpkılıç Baskırt E, Ak G, Zulfıkar B. Oral and general healthrelated quality of life among young patients with haemophilia. Haemophilia 2009;15(1):193-198.

15. Reddy NV, Reddy KS, Niharika P, Reddy MA, Danaeswari V, Noorjahan M. Oral Health Status and Treatment Needs among 
Hemophilic Children in Hyderabad, Telangana, India. Int J Clin Pediatr Dent 2019;12(1):30-32.

16. Babu NSV, Shah M, Patel P. Oral health status in children with haemophilia - a comparative study. J Haemoph Pract 2016;3(2):43-47.

17. Goldmann G, Berens C, Marquardt N, Reich R, Oldenburg $\mathrm{J}$, Wenghoefer $\mathrm{M}$. No increased bleeding risk for oral surgery in patients with severe congenital bleeding disorders due to intense perioperative management. Oral Maxillofac Surg 2015;19(2):195-200.

18. Khokhar R, Hussain A, Khan M, Hajnour M, Qureshi S, Aqil M. Anesthetic management of patient with hemophilia a undergoing emergency ventriculoperitoneal shunting: A case report and review of literature. Saudi J Anaesth 2016;10(4):474.
19. Frachon $X$, Pommereuil $M$, Berthier AM, et al. Management options for dental extraction in hemophiliacs: A study of 55 extractions (2000-2002). Oral Surgery, Oral Med Oral Pathol Oral Radiol Endodontology 2005;99(3):270-275.

20. Zanon, Martinelli, Bacci, Zerbinati, Girolami. Proposal of a standard approach to dental extraction in haemophilia patients. A case-control study with good results. Haemophilia 2000;6(5):533-536.

21. Brewer A, Correa M. Guidelines for dental treatment of patients with inherited bleeding disorders. Haemophilia 2005;11(40):504-509. 